\title{
Operating Performance Assessment of Fire Alarm System Based on BP Neural Network
}

\author{
$\mathrm{Na} \mathrm{Qu}{ }^{1}$, Jiwei Zhu ${ }^{1}$ \& Jiahao Wang ${ }^{1}$ \\ 1 School of Safety Engineering, Shenyang Aerospace University, Shenyang 110136, China.
}

Keywords: Fire alarm system; Operating performance assessment; Analytic hierarchy process (AHP); BP neural network.

\begin{abstract}
With the rapid development of super large buildings, monitoring of fire hidden danger is much more difficult than ever. Whether fire alarm system is effective or not directly affects the ability of controlling fire and protecting people's lives and property. Operating performance assessment of fire alarm system is to assess intact effectiveness of the system by inspection and test. Analytic hierarchy process (AHP) is used to establish index system of operating performance. BP neural network algorithm is used to calculate the weight of each index so as to establish the assessment model of operating performance. It shows that the assessment model achieves better performance by MATLAB simulation and can provide reference for the system design and management.
\end{abstract}

\section{Introduction}

Fire alarm system, which consists of automatic alarm part and linkage controlling part, is responsible for fire monitoring and fire command work. Operating performance of the fire alarm system directly affects the ability of controlling fire and protecting people's lives and property.

In 2009, Zhao Hairong used AHP to determine the weight of each indicator and gave the evaluation model of automatic fire alarm system [1]. Song Liwei studied application performance evaluation on automatic fire alarm system in metro. Requirements, evaluation index system, evaluation process and score model of application performance evaluation on automatic fir e alarm system in metro were proposed. But scoring model is not clear enough [2]. In 2010, Sun Yingying developed the response measures to improve the application efficiency of fire alarm system, but did not put forward the model of effectiveness evaluation [3]. Ma Yudong put forward the improvement measures of automatic fire alarm system performance but didn't establish effectiveness evaluation model [4]. Zhang Limin introduced the classification and decision of the evaluation index and decided the evaluation method and grading standards of the fire command automation systems [5]. In 2011, Z.G. Liu presented the results of the full-scale experiments conducted in a laboratory tunnel facility under longitudinal airflow conditions. The performance of nine fire detection systems representing five types of the fire detection technologies for road tunnel applications was investigated using representative tunnel fire scenarios [6]. Marty Ahrens provided background about smoke alarms in the general population and in unreported fires by the findings from the Consumer Product Safety Commission’s 2004 to 2005 Residential Fire Survey [7]. In 2012, Zhang Zhenna carried out simulation and experimental investigation on the early aspirated smoke detection system to analyze the response performance of fire detectors located at the smoke sampling pipes [8]. Zhang Limin elected AHP to identify multi-criteria comprehensive weighs of the third-grade indexes and constructed dual-binding evaluation model of fire command automation system [9]. In 2013, Ren Guosheng analyzed the current application performance problems of fire alarm product from multiple perspectives and put forward corresponding countermeasures [10]. Ionuţ-Lucian presented a fire detection algorithm proposal based on fuzzy expert systems which include the human experience and whose design is based on experimental data following real scale fire tests[11].

Analytic hierarchy process (AHP) is used to establish index system of operating performance assessment. BP neural network algorithm is used to calculate the weight of each index so as to establish the assessment model of operating performance. It shows that the assessment model 
achieves better performance by MATLAB simulation. The calculation procedures of the system assessment and a case on calculating operating performance, which can provide reference for the system design and management, are given.

\section{Operating Performance Assessment Algorithm Design}

The analytic hierarchy process (AHP) is a structured technique for organizing and analyzing complex decisions and commonly used in performance assessment. AHP decomposes the problem into a hierarchy of more easy sub-problems which can be analyzed independently.

The AHP presents a complex nonlinear relationship and uncertainty when it determines the weight of indicators of fire alarm system operating performance. Artificial neural network provides a powerful tool for dealing with this kind of nonlinear relationship. BP neural network, which is an effective and common neural network algorithm and has fast calculated speed and strong learning ability, can be used to calculate the weight.

\subsection{Analytic hierarchy process on operating performance}

First of all, AHP is used to establish the operating performance index system of fire alarm system (see Table 1) [12].

\subsubsection{System utilization}

The system utilization is the ratio of controller in perfect working time and the working time. The formula is

$$
P_{t}=\frac{n T_{t}-T_{s}}{n T_{t}} \times 100 \%
$$

$P_{t}$ is system utilization . $T_{t}$ is the total running time of the system that is the interval from system

acceptance to evaluation. $T_{s}$ is the controller downtime. $n_{\text {is }}$ the total number of controller.

Table 1 operating performance index system

\begin{tabular}{|c|c|}
\hline \multicolumn{2}{|l|}{ Assessment indexes } \\
\hline Primary indexes & Secondary indexes \\
\hline System utilization (B1) & System utilization (C1) \\
\hline \multirow{5}{*}{$\begin{array}{l}\text { Equipment availability } \\
\text { (B2) }\end{array}$} & Controller availability (C2) \\
\hline & Detector availability( C3) \\
\hline & module availability (C4) \\
\hline & Fire hydrant button availability (C5) \\
\hline & $\begin{array}{l}\text { Manual warning button availability } \\
\text { (C6) }\end{array}$ \\
\hline \multirow[t]{4}{*}{$\begin{array}{l}\text { Detection effectiveness } \\
\text { (B3) }\end{array}$} & $\begin{array}{l}\text { Fire alarm and linkage load } \\
\text { performance(C7) }\end{array}$ \\
\hline & Black smoke response (C8) \\
\hline & $\begin{array}{l}\text { Smoldering fire / smoke fire response } \\
\text { (C9) }\end{array}$ \\
\hline & Detection dysfunction (C10) \\
\hline \multirow[t]{3}{*}{$\begin{array}{l}\text { Evacuation effectiveness } \\
\text { (B4) }\end{array}$} & $\begin{array}{l}\text { Evacuation staircase linkage } \\
\text { performance (C11) }\end{array}$ \\
\hline & $\begin{array}{l}\text { Complex regional evacuation linkage } \\
\text { performance (C12) }\end{array}$ \\
\hline & $\begin{array}{l}\text { Elevator and evacuation passage } \\
\text { linkage performance (C13) }\end{array}$ \\
\hline $\begin{array}{l}\text { Fire separation } \\
\text { effectiveness (B5) }\end{array}$ & $\begin{array}{l}\text { Fire separation of shared space } \\
\text { linkage performance }(\mathrm{C} 14)\end{array}$ \\
\hline
\end{tabular}




\begin{tabular}{|l|l|}
\hline \multirow{2}{*}{$\begin{array}{l}\text { Fire fighting effectiveness } \\
\text { (B6) }\end{array}$} & $\begin{array}{l}\text { fire valve linkage performance (C15) } \\
\text { important fire extinguishing } \\
\text { equipment (C16) }\end{array}$ \\
\cline { 2 - 2 } & $\begin{array}{l}\text { Fire hydrant button of end of the } \\
\text { pipeline to open the pump } \\
\text { performance (C17) }\end{array}$ \\
\hline sprinkler system linkage performance \\
(C18) fire \\
\hline $\begin{array}{l}\text { Gas, foam, dry powder fire } \\
\text { extinguishing system linkage } \\
\text { performance (C19) }\end{array}$ \\
\hline
\end{tabular}

\subsubsection{Equipment availability}

Equipment availability is the percentage of technology performance intact equipment quantity accounted for all the equipment in the system.

Controller availability is

$$
P_{e}=\frac{\sum_{i=1}^{n} P_{i}}{n} \times 100 \%
$$

$P_{e}$ is controller availability. ${ }^{P_{i}}$ is each controller of the system availability. $\mathrm{N}$ is the total number of controller.

Statistics of the fire detectors which are broken-down and shielding by the controller query function can get the query intact rate of fire detector. The formula is

$$
P_{Q}=\frac{N-N_{t}}{N} \times 100 \%
$$

$P_{Q}$ is query intact rate of fire detector. $\mathrm{N}$ is the total number of detector. $N_{t}$ is the total number of the fire detectors which are broken-down and shielding.

Alarm response performance of fire detector in important and fire danger position is checked. If the detector is capable of normal alarm, the detector is judged to be a qualified. The formula is

$$
R_{c}=\frac{N_{q}}{n} \times 100 \%
$$

$R_{c}$ is qualified rate of Spot checks of the detector. $N_{q}$ is number of qualified detector. $\mathrm{n}$ is number of Spot checks of the detector.

Detector availability is product of query intact rate of fire detector and qualified rate of Spot checks of the detector. The formula is

$$
P_{c}=P_{Q} \times R_{C}
$$

The calculation method of intact rate of module, manual alarm button and fire hydrant button is the same as detector.

\subsubsection{Detection effectiveness}

Detection effectiveness is judged according to the times of omission by simulated fire experiment and historical records query.

\subsubsection{Evacuation effectiveness}

Evacuation effectiveness is judged according to the corresponding equipment in action by simulated fire experiment and historical records query.

\subsubsection{Fire separation effectiveness}

Fire separation effectiveness is judged according to the corresponding equipment in action by simulated fire experiment and historical records query.

\subsubsection{Fire fighting effectiveness}

Fire fighting effectiveness is judged according to the corresponding equipment in action by 
simulated fire experiment and historical records query.

\subsection{BP neural network model}

BP (Back Propagation) neural network consists of positive-going information transition and erroneous opposite-going transition. The input layer is responsible for receiving from the outside world and transfers to the hidden layer. The hidden layer is responsible for internal information processing and information transformation. According to the ability of information demand, the hidden layer can be designed as single hidden layer or several hidden layers. The last hidden layer transfers the information to the output layer. After further processing, positive-going information transition has been completed. When the actual output does not accord with the expected output, erroneous opposite-going transition begins. Error transfers in reverse from the output layer to the hidden layer and input layer. Process of positive-going information transition and erroneous opposite-going transition is the process that each layer weights are adjusted and the neural network is trained. The process has been completed when the network output error is reduced to acceptable levels or achieved the predetermined learning times.

\subsubsection{Input and output}

The inputs of neural network model are secondary indexes that get from AHP and which are defined as $\mathrm{Ci}(\mathrm{i}=1 \cdots 19)$. The output of neural network model is operating performance of fire alarm system and which is defined as A. The range of input and output is $[0,1]$. Output between 0.9 and 1.0 is excellent and shows that the system has played a excellent performance and small problems can be resolved by maintenance and management personnel. Output between 0.8 and 0.9 is good and shows that the system has played a good performance and the problem must be resolved by a professional repair personnel within the allotted time. Output between 0.7 and 0.8 is general and shows that the system has played a general performance. But the owners should immediately organize professional and technical personnel to repair the system problems. Output below 0.7 is poor and shows that the system has not been able to play the main role. There are fatal factors influencing the operation performance and must be resolved. It is proposed that the whole system is replaced, if the repair expense is high and the system operating time can't be guaranteed.

\subsubsection{Neural network hidden layer and the hidden layer nodes}

One hidden layer and five hidden layer nodes is selected in network model.

\subsubsection{Training samples}

Groups of sample data are used to train the BP neural network. In general, the larger number of training samples the more abundant experience of neural network and more close to the real the evaluation result will be achieved. However, due to the limitation of the reality, the number of samples can't be infinite. In general, if the number of samples is greater than 10, the neural network that be trained out will have good performance. In addition, the training sample must meet the same rule. If not, neural network model will be not practical. For example, training sample in the 80's cannot use to evaluate current fire alarm system. In order to test performance of the trained neural network model, some samples will be retained. 16 groups of sample data are chosen of fire alarm system in college, universities, companies, shopping malls and other places through the simulation of fire experiment, the historical record and expert scoring method. The sample data from first to fourteenth groups is used as training samples. The sample data of the fifteenth group and sixteenth group is used as test sample.

\subsection{MATLAB simulation}

Operating performance assessment model is simulated by MATLAB. Operating performance assessment model is simulated by MATLAB. The program code is as follows.

clc

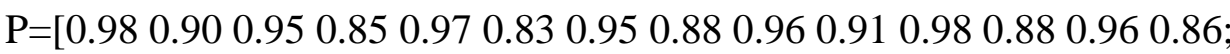

$$
\begin{aligned}
& 1.000 .951 .000 .900 .990 .891 .000 .900 .970 .941 .000 .900 .940 .89 \text {; }
\end{aligned}
$$

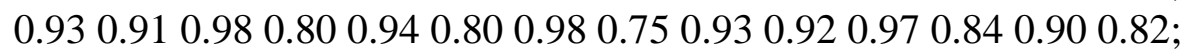

$$
\begin{aligned}
& 0.980 .900 .920 .910 .980 .850 .890 .930 .980 .930 .950 .980 .960 .81 \text {; } \\
& 1.000 .981 .000 .920 .970 .950 .960 .920 .990 .960 .980 .920 .970 .94 \text {; }
\end{aligned}
$$


1.000 .991 .000 .930 .980 .941 .000 .910 .980 .950 .990 .910 .970 .90 ; 0.980 .940 .960 .800 .900 .910 .960 .800 .990 .930 .960 .800 .950 .82 ; 0.960 .960 .990 .820 .950 .900 .970 .800 .950 .940 .990 .820 .940 .81 ; 0.960 .920 .960 .890 .960 .920 .960 .880 .970 .940 .980 .890 .940 .90 ; 1.000 .951 .000 .930 .900 .891 .000 .910 .980 .970 .980 .930 .970 .90 ; 0.970 .940 .970 .820 .910 .910 .970 .820 .960 .970 .970 .820 .960 .81 ; 0.950 .950 .960 .810 .940 .900 .950 .800 .960 .960 .980 .810 .930 .80 ; 0.930 .930 .970 .920 .890 .880 .970 .920 .940 .940 .970 .860 .920 .83 ; 0.960 .950 .960 .950 .940 .860 .960 .900 .950 .960 .960 .820 .950 .85 ; 0.950 .900 .950 .810 .930 .800 .950 .790 .940 .910 .970 .810 .940 .80 ; 0.910 .880 .920 .840 .890 .810 .930 .830 .900 .870 .930 .840 .890 .82 ; 0.940 .920 .950 .900 .930 .910 .940 .880 .900 .940 .960 .900 .880 .88 ; 0.960 .930 .970 .850 .930 .930 .950 .890 .910 .930 .950 .920 .930 .93 ; $0.900 .750 .910 .600 .850 .660 .920 .800 .940 .810 .980 .790 .860 .74]$;

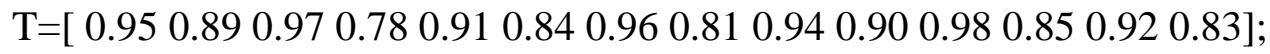
net=newff(minmax(P),[19,5,1],\{'tansig','tansig','purelin'\},'traingdm');

net.trainParam.show $=5000$;

net.trainParam.lr=0.05;

net.trainParam.mc $=0.95$;

net.trainParam.epochs $=5000$;

net.trainParam.goal $=1 \mathrm{e}-5 * 100$

[net tr]=train(net,P,T);

After 982 times of learning and training, the global error of network is less than or equal to 0.001 which is the preset precision and network is convergent.

The fifteenth sample was used to detect the performance of trained neural network.

ptest=[ 0.92; 0.92; 0.90; 0.95;0.89; 0.95; 0.94; 0.96; 0.92; 0.93; 0.97; 0.95; 0.93; 0.96; 0.95; 0.88; $0.94 ; 0.93 ; 0.88]$;

>> a $=\operatorname{sim}($ net,ptest)

$\mathrm{a}=0.8986$

The sixteenth sample was used to detect the performance of trained neural network.

>> ptest=[ $0.94 ; 0.95 ; 0.89 ; 0.96 ; 0.95 ; 0.93 ; 0.91 ; 0.97 ; 0.90 ; 0.98 ; 0.96 ; 0.94 ; 0.92 ; 0.94 ; 0.93 ; 0.91 ;$ $0.92 ; 0.98 ; 0.90]$;

$>>\mathrm{a}=\operatorname{sim}($ net,ptest)

$\mathrm{a}=0.9056$

We can see that actual output $(0.8986,0.9056)$ and the target output $(0.90,0.91)$ had little difference. It illustrates that the performance of the neural network model is good. 


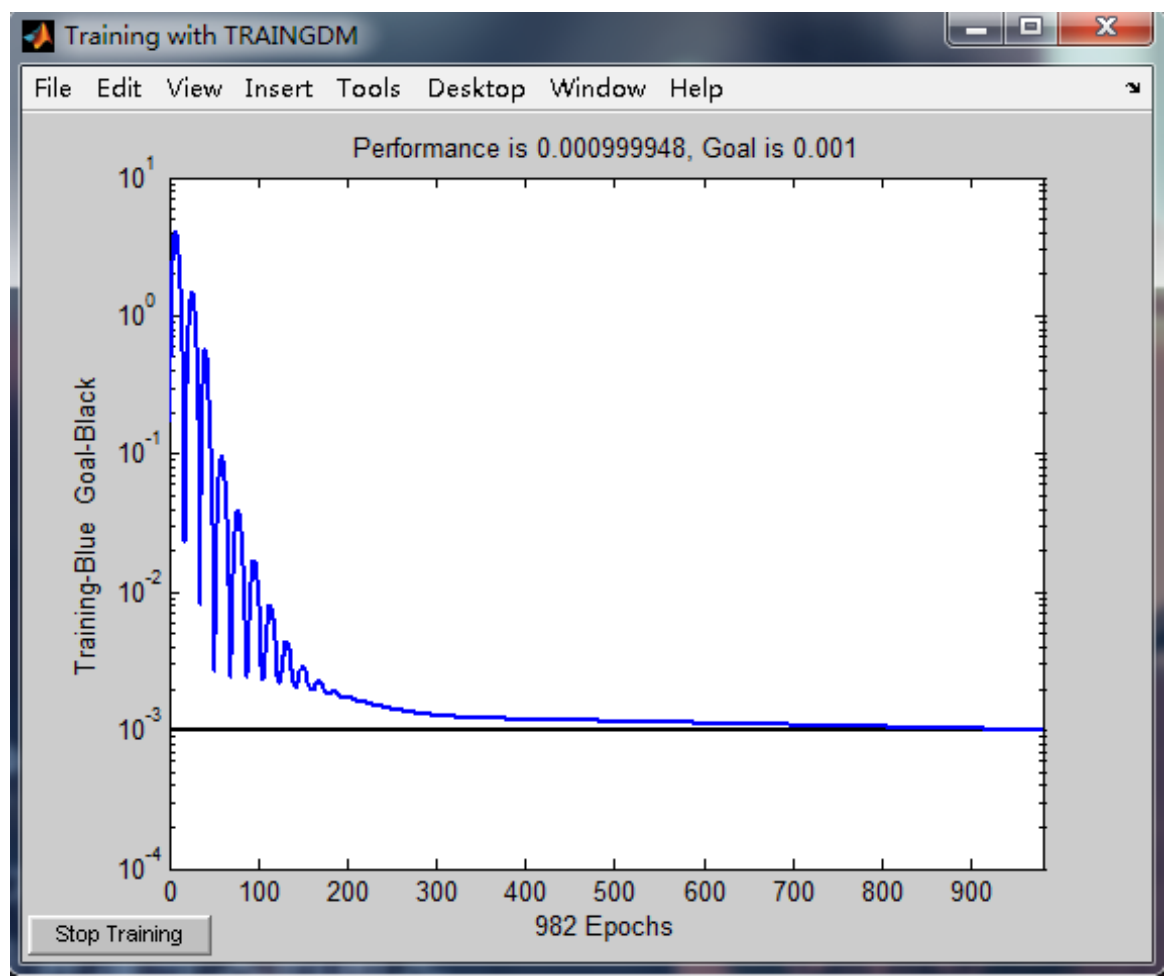

Fig.1 Network training

\section{A Case}

The fire alarm system operating performance of Shenyang aerospace university library is assessed in order to illustrate the effectiveness of assessment model. The assessment data of secondary indexes is obtained by the analysis and calculation of fire alarm system operating information of Shenyang aerospace university library three years and the discussion of the experts. ptest $=[1.00 ; 0.98 ; 0.95 ; 0.96 ; 1.00 ; 1.00 ; 0.96 ; 1.00 ; 1.00 ; 0.95 ; 0.98 ; 1.00 ; 1.00 ; 0.98 ; 0.98 ; 0.97 ; 0.99 ; 0.99 ; 0$. 90];

$$
\begin{aligned}
& \mathrm{a}=\operatorname{sim} \text { (net,ptest) } \\
& \mathrm{a}=0.9355
\end{aligned}
$$

The assessment result can be seen that the fire alarm system operating performance of Shenyang aerospace university library is excellent. The system only has small problems which can be resolved by maintenance and management personnel.

\section{Conclusions}

(a)The operating performance assessment indexes of fire alarm system are obtained by the analytic hierarchy process.

(b) The assessment model of operating performance is constructed by BP neural network algorithm.

(c) The assessment model of operating performance is simulated by MATLAB. It illustrates that the performance of the neural network model is good.

(d) A case of operating performance assessment is given. The result is 0.9355 and the system operating performance is excellent. The results of the assessment is effective.

\section{References}

[1] Zhao Hairong, Reliability Analysis and Application Efficiency Evaluation of Automatic Fire Alarm System. Northeastern University, pp.58-70, 2009.

[2]SONG Liwei, Song Lidan, Zhao Hairong, Application performance evaluation on automatic fire alarm system of metro: Fire Science and Technology, pp. 516-518, 2009. 
[3] Sun Yingying, Discussion on improving the automatic fire alarm system performance: High-Technology \& Industrialization, pp.97-98, 2010.

[4] Ma Yudong, Some thoughts about the automatic fire alarm product efficacy: Market Modernization, pp. 172-173, 2010.

[5] Zhang Limin, Pei Jianguo, Zhou Wei, Research on the effectiveness evaluation index system of f ire command automation system: Fire Science and Technology, pp.311-313,2010.

[6] Z. G. Liu, Investigation on the performance of fire detection systems for tunnel applications-Part 2: Full-scale experiments under lngitudinal airflow conditions: Fire Technology, pp. 191-220,2011.

[7]Marty Ahrens, Smoke Alarm Presence and Performance in U.S. Home Fires: Fire Technology, pp. 699-720,2011.

[8]Zhang Zhenna, Zhang Qin, Performance Study on Fire Alarm System in Large Space Buildings: Recent Advances in Computer Science and Information Engineering, pp. 69-73,2012.

[9]Zhang Limin, Research on the Efficiency Evaluation Model of Fire Command Automation System: Advanced Materials Research 383-390, pp. 2492-2495, 2012.

[10] Ren Guosheng, Current situation and countermeasures on the efficacy of automatic fire alarm product: China CIO News, pp. 82-84,2013.

[11] Ionuţ-Lucian, Radu, Mircea, Efficiency increase for electrical fire detection and alarm systems through implementation of fuzzy expert systems , Electrical Engineering, pp.251-266,2013.

[12] Performance Assessment of Fire Detection and Alarm System, The People's Republic of China National Standardization Technical Guidance Document., GB/Z24978-2010. 